\title{
Lixiviação de diuron, hexazinone e sulfometuron-methyl em formulação comercial e isoladamente em dois solos contrastantes ${ }^{1}$
}

\author{
Diuron, hexazinone and sulfometuron-methyl leaching separately and in \\ commercial formulation in two contrasting soils
}

\author{
Danilo de Brito Garcia ${ }^{2}$; Samuel Neves Rodrigues Alves³ ${ }^{3}$ João Batista Cason ${ }^{3}$; Pedro Jacob \\ Christoffoleti $^{4}$
}

\begin{abstract}
Resumo - O objetivo desse trabalho foi avaliar a influência de texturas contrastantes (argilosa e areia franca) na lixiviação de diuron, hexazinone e sulfometuron-methyl em formulação comercial (D+H+SMM) e aplicados isoladamente, quando submetidos à 0 e $40 \mathrm{~mm}$ de simulação de precipitação. O experimento consistiu na aplicação de diuron + hexazinone + sulfometuronmethyl $\left(1386,9+391+33,35 \mathrm{~g} \mathrm{ha}^{-1}\right)$, hexazinone $\left(391 \mathrm{~g} \mathrm{ha}^{-1}\right)$, diuron $\left(1386,9 \mathrm{~g} \mathrm{ha}^{-1}\right) \mathrm{e}$ sulfometuron-methyl $\left(33,35 \mathrm{~g} \mathrm{ha}^{-1}\right)$ em colunas de solo montadas em tubos de PVC. Um dia após a aplicação, metade das colunas recebeu simulação de precipitação de $40 \mathrm{~mm}$ e a planta daninha Ipomoea triloba foi semeada. Aos 21 e 30 dias após a semeadura foi feita avaliação de porcentagem de controle. Para o solo de textura argilosa, os herbicidas $\mathrm{D}+\mathrm{H}+\mathrm{SMM}$ e hexazinone chegaram a aproximadamente 10 e $13 \mathrm{~cm}$ de profundidade com 0 e $40 \mathrm{~mm}$, respectivamente. No solo de textura arenosa, a lixiviação desses herbicidas foi evidente até os $20 \mathrm{~cm}$ de profundidade, com $40 \mathrm{~mm}$ de precipitação. Para os herbicidas diuron e sulfometuron-methyl as lixiviações tenderam a se aproximar para o solo de textura argilosa com $40 \mathrm{~mm}$ e para o solo de textura arenosa nas duas simulações de precipitação. Hexazinone e D+H+SMM foram os herbicidas que apresentaram maior tendência de lixiviação, facilitada no solo de textura arenosa. Já a lixiviação dos herbicidas diuron e sulfometuron-methyl foi baixa, o que expõe a influência do hexazinone na lixiviação da formulação comercial avaliada.
\end{abstract}

Palavras-chave: Cana-de-açúcar, herbicida, textura, corda-de-viola

\begin{abstract}
The objective of this research was to evaluate contrasting textures soils (clay and loamy sand) in the leaching of diuron + hexazinone + sulfometuron-methyl $(1386.9+391+$ $\left.33.35 \mathrm{~g} \mathrm{ha}^{-1}\right)$ commercial formulation, and also hexazinone (391 $\left.\mathrm{g} \mathrm{ha}^{-1}\right)$, diuron (1386.9 $\left.\mathrm{g} \mathrm{ha}^{-1}\right)$ and sulfometuron-methyl $\left(33.35 \mathrm{~g} \mathrm{ha}^{-1}\right)$, in soil columns mounted in PVC pipes. One day after the herbicide application, half of the columns received $40 \mathrm{~mm}$ of simulated rainfall and Ipomoea triloba weed was sown. At 21 and 30 days after sowing, it was accomplished the evaluation about percentage of weed control. For the clay texture soil, diuron + hexazinone + sulfometuronmethyl and hexazinone herbicides reached approximately 10 to $13 \mathrm{~cm}$ deep with 0 and $40 \mathrm{~mm}$, respectively. In loamy sand texture soil, herbicides leaching was evident up to $20 \mathrm{~cm}$ deep, with $40 \mathrm{~mm}$ of precipitation. For diuron and sulfometuron-methyl herbicides, leaching tended to approach to clay texture soil with $40 \mathrm{~mm}$ and to loamy sand texture soil in the two simulated

\footnotetext{
${ }^{1}$ Recebido para publicação em 08/06/2012 e aceito em 30/08/2012.

${ }^{2}$ Mestrando do Programa de Pós-Graduação em Fitotecnia, Escola Superior de Agricultura "Luiz de Queiroz"ESALQ/USP. Avenida Pádua Dias, 11, Piracicaba/SP, Brasil - CEP: 13418-900. E-mail: danilo.bgarcia@gmail.com;

${ }^{3}$ DuPont do Brasil S.A. Rua Bortolo Ferro, 500A - Poço Fundo - Paulínia/ SP, Brasil - CEP 13140-000;

${ }^{4}$ Professor Associado, Escola Superior de Agricultura “Luiz de Queiroz"-ESALQ/USP.
} 
Garcia et al.

precipitations. Hexazinone and $\mathrm{D}+\mathrm{H}+\mathrm{SMM}$ were the herbicides that presented the highest trend to leaching, facilitated in loamy sand texture soil. Diuron and sulfometuron-methyl herbicides' leaching was lower, fact that exposes hexazinone influence in the leaching of the evaluated commercial formulation.

Keywords: Sugarcane, herbicide, texture, morning glory

\section{Introdução}

A lixiviação é o fenômeno de transporte em profundidade, por meio do perfil do solo, da fração dos sólidos dissolvidos em sua solução (Gebler \& Spadotto, 2008). O comportamento e o destino dos herbicidas no ambiente dependem de fatores externos a sua composição, como temperatura e umidade, presença de matéria orgânica, modo de aplicação, entre outros. Além disso, são fundamentais as propriedades intrínsecas do composto, como a conformação da estrutura molecular do ingrediente ativo e as características físico-químicas, que irão determinar sua distribuição na atmosfera, no solo, na água e na biota, onde então passará a sofrer ações de indisponibilização (Gebler \& Spadotto, 2008). A estrutura química do produto fitossanitário (ingrediente ativo) influencia a sua eficácia no controle de plantas daninhas, pragas e doenças das culturas, além de sua mobilidade e degradabilidade (Pessoa et al., 2007).

Herbicidas aplicados em solos e que se movem facilmente através deste podem falhar no controle das plantas daninhas devido à diluição e lixiviação. Além disso, a alta mobilidade pode causar danos à vegetação não alvo, e potencialmente, contaminar recursos hídricos (Regitano et al., 2002).

Compostos ionizáveis compreendem ácidos e/ou bases fracas como grupos funcionais. Como consequência, podem ser parcialmente ionizados na amplitude de $\mathrm{pH}$ normalmente encontrada nos solos, o que afeta fortemente sua reatividade no solo. A adsorção de compostos orgânicos neutros nos solos ocorre principalmente por particionamento hidrofóbico, enquanto que uma série de outros mecanismos são postulados para a adsorção de produtos fitossanitários ionizáveis. É essencial que esse comportamento específico seja reconhecido em procedimentos de avaliação de riscos para se obter uma análise robusta de seu provável comportamento (Kah \& Brown, 2006).

Muitos estudos demonstram que a adsorção de químicos orgânicos (produtos fitossanitários não iônicos) nos solos é feita principalmente pela matéria orgânica, mesmo que a estrutura e propriedades dos constituintes orgânicos não sejam ainda claramente entendidas (Kah \& Brown, 2006). Além disso, os mesmos autores afirmam que os componentes inorgânicos e orgânicos do solo funcionam mais como uma unidade do que como entidades separadas e sua interação ainda não é totalmente compreendida.

Em qualquer análise de localização do herbicida no solo, a lixiviação entra como uma importante variável, e as equações que descrevem o transporte de massa do soluto na solução do solo irão variar segundo a umidade contida no solo e a porosidade deste (Gebler \& Spadotto, 2008).

Diuron é uma molécula herbicida não ionizável (coeficiente de dissociação $\mathrm{pK}_{\mathrm{a}}$ não aplicável) e é considerado um herbicida pouco móvel e de baixa solubilidade em água. Hexazinone tem o coeficiente de dissociação $\mathrm{pK}_{\mathrm{a}}$ de 2,2 e é uma base fraca, considerado um herbicida móvel e altamente solúvel em água. Sulfometuon-methyl tem $\mathrm{pK}_{\mathrm{a}}$ de 5,2 e é um ácido fraco, considerado moderadamente móvel e solúvel em água (University of Hertfordshire, 2011)

Portanto, o objetivo deste trabalho foi avaliar o efeito de texturas contrastantes de 
Garcia et al.

solo na lixiviação de diuron, hexazinone e sulfometuron-methyl aplicados em formulação comercial e isoladamente.

\section{Material e Métodos}

$\mathrm{O}$ experimento foi conduzido de janeiro a fevereiro de 2011 em casa-de-vegetação. As amostras dos solos utilizados no experimento foram retiradas da sub-superfície de dois solos e depois de secas, foram peneiradas em peneira com malha de $2 \mathrm{~mm}$. As propriedades químicas dos solos utilizados no experimento encontram-se na Tabela 1 e as propriedades físicas estão apresentadas na Tabela 2.

Tabela 1. Propriedades químicas dos solos utilizados no experimento.

\begin{tabular}{|c|c|c|c|c|c|c|c|c|c|c|}
\hline \multirow{2}{*}{ ID* } & $\mathrm{pH}$ & M.O. & $P$ resina & $\mathrm{K}$ & $\mathrm{Ca}$ & $\mathrm{Mg}$ & $\mathrm{H}+\mathrm{Al}$ & CTC & SB & $\mathrm{V}$ \\
\hline & $\mathrm{CaCl}_{2}$ & $\mathrm{~g} \mathrm{dm}^{-3}$ & $\mathrm{mg} \mathrm{dm}^{-3}$ & \multicolumn{6}{|c|}{$\mathrm{cmol}_{\mathrm{c}} \mathrm{dm}^{-3}$} & $\%$ \\
\hline A & 4,8 & 24 & 12 & 0,14 & 2,4 & 0,9 & 3,4 & 6,84 & 3,44 & 50,3 \\
\hline B & 4,5 & 10 & 3 & 0,05 & 0,7 & 0,3 & 3,4 & 4,45 & 1,05 & 23,6 \\
\hline
\end{tabular}

Unithal Laboratório Agronômico, Campinas - SP; *ID = Identificação.

Tabela 2. Propriedades físicas dos solos utilizados no experimento.

\begin{tabular}{|c|c|c|c|c|c|}
\hline \multirow{2}{*}{ ID* } & Areia & Silte & Argila & \multirow{2}{*}{ Classe Textural } & \multirow{2}{*}{ Origem } \\
\hline & & $\%$ & & & \\
\hline $\mathrm{A}$ & 27,3 & 13,7 & 59,0 & Argila & Paulínia - SP \\
\hline $\mathrm{B}$ & 86,1 & 2,4 & 11,5 & Areia franca & Bofete - SP \\
\hline
\end{tabular}

Unithal Laboratório Agronômico, Campinas - SP; *ID = Identificação.

As unidades experimentais consistiram em colunas de solo montadas em tubos de PVC de $12 \mathrm{~cm}$ de diâmetro e $50 \mathrm{~cm}$ de comprimento, com 16 furos (distanciados a cada $3 \mathrm{~cm}$ ). Os tubos foram preenchidos internamente por uma camada de parafina a fim de evitar escorrimento lateral da solução do solo. $\mathrm{Na}$ base das colunas, para reter o solo e permitir a drenagem, foram colocadas telas de sombrite $(50 \%)$. As colunas foram submetidas à irrigação por capilaridade, até o solo se apresentar saturado no topo, permitindo-se em seguida o escoamento da água durante 24 horas, para que este atingisse umidade próxima da capacidade de campo.

Os herbicidas foram aplicados com auxílio de pulverizador costal à pressão constante, mantida por $\mathrm{CO}_{2}$ comprimido, de 25 PSI, munido de barra com duas pontas de pulverização XR 110.02, espaçadas de $0,5 \mathrm{~m}$, com consumo de calda correspondente a $200 \mathrm{~L}$ $\mathrm{ha}^{-1}$. O experimento consistiu na aplicação dos seguintes tratamentos: diuron + hexazinone + sulfometuron-methyl $(1386,9+391+33,35 \mathrm{~g}$ $\left.\mathrm{ha}^{-1}\right)$, hexazinone (391 $\left.\mathrm{g} \mathrm{ha}^{-1}\right)$, diuron $(1386,9 \mathrm{~g}$ $\left.\mathrm{ha}^{-1}\right)$ e sulfometuron-methyl (33,35 $\left.\mathrm{g} \mathrm{ha}^{-1}\right)$, arranjados em esquema fatorial 5 x 16, sendo 4 herbicidas mais a testemunha sem aplicação e 16 os fatores profundidades (a cada $3 \mathrm{~cm}$ ), avaliados dentro de cada precipitação pluvial simulada (0 e $40 \mathrm{~mm}$ ).

Um dia após a aplicação dos herbicidas, os tubos destinados a receber $40 \mathrm{~mm}$ de chuva foram colocados sob simulador de chuva com intensidade de precipitação de aproximadamente $1 \mathrm{~mm} \mathrm{~min}^{-1}$, durante o tempo necessário para se aplicar a lâmina de $40 \mathrm{~mm}$. Após a simulação, as colunas ficaram em repouso por 72 horas, quando então foram colocadas na posição horizontal. Em cada uma das 16 subdivisões da coluna (espaçadas de 3 $\mathrm{cm}$ ), foram semeadas duas sementes de Ipomoea triloba com dormência previamente quebrada em água fervente. Aos 21 e 30 dias após a semeadura, foram realizadas avaliações visuais de porcentagem de controle, atribuindo- 
Garcia et al.

se notas de 0 a $100 \%$ sendo 0 a ausência de sintomas e $100 \%$ a morte das plantas.

Os dados foram submetidos à análise de variância e quando detectada a influência da profundidade, fez-se o uso de regressões nãolineares para descrever a lixiviação dos herbicidas nas colunas de solo, utilizando-se o programa SIGMAPLOT.

\section{Resultados e Discussão}

Houve interação significativa entre os herbicidas e as profundidades, para 0 e $40 \mathrm{~mm}$, indicando que os herbicidas moveram-se de forma diferente no perfil das colunas. $\mathrm{Na}$ Figura 1 estão apresentados os resultados da primeira avaliação (21 DAS) da corda-de-viola.

A
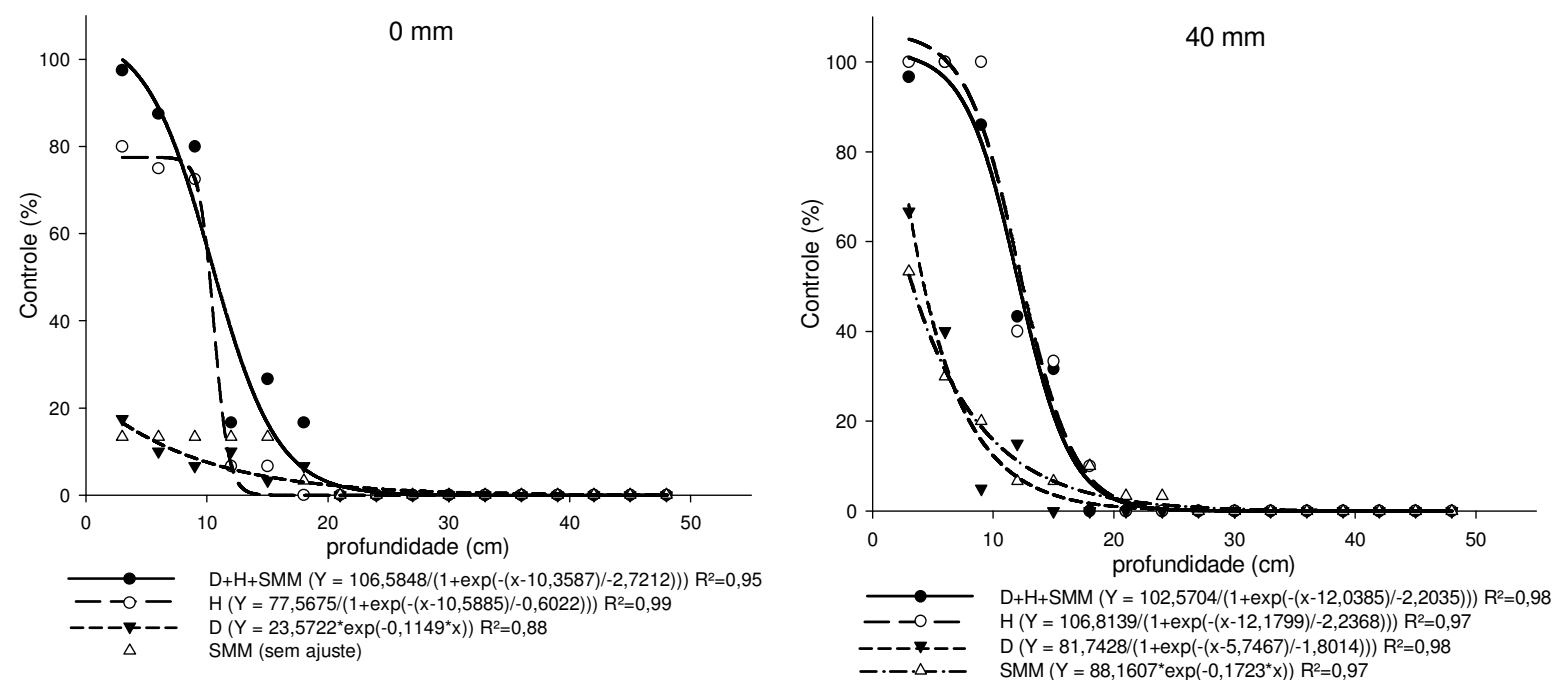

B
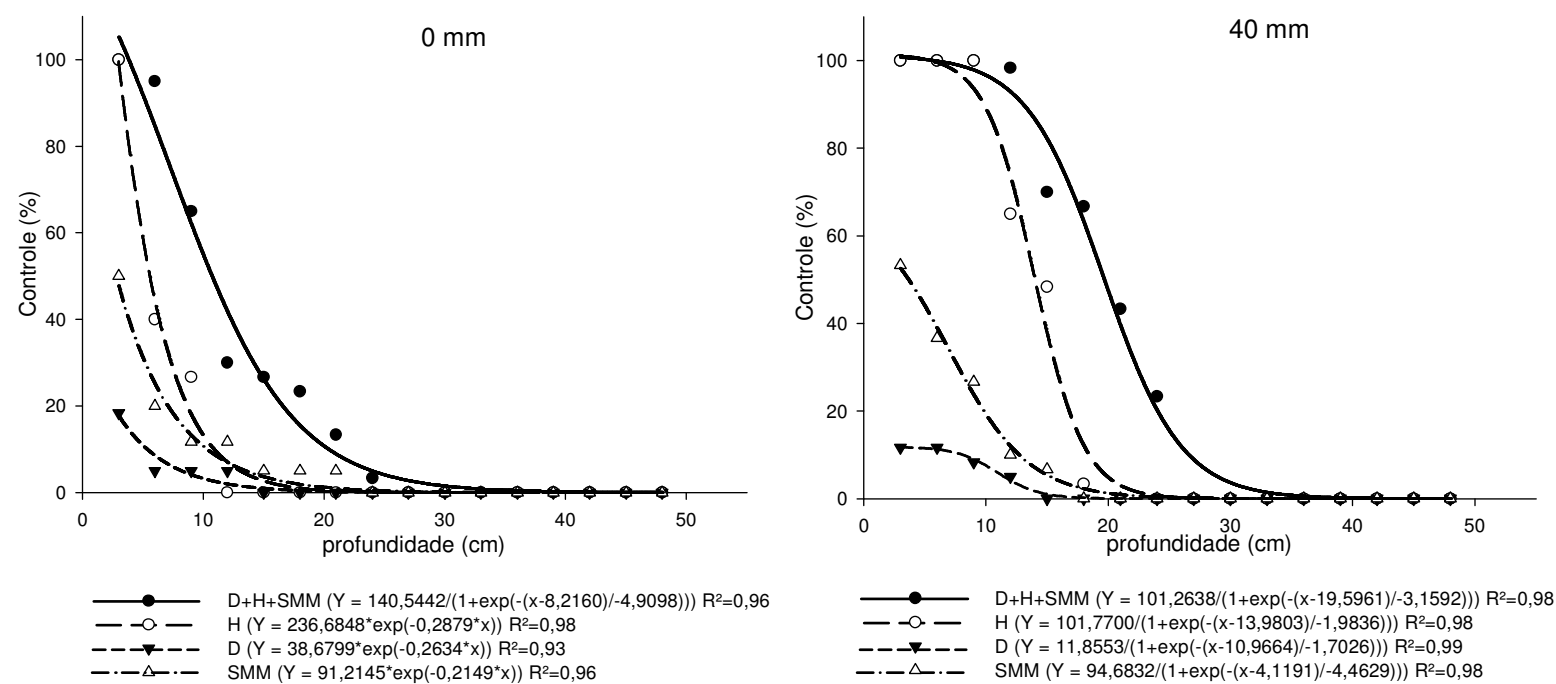

Figura 1. Lixiviação dos herbicidas diuron + hexazinone + sulfometuron-methyl (D+H+SMM), hexazinone (H), diuron (D) e sulfometuron-methyl (SMM) no solo de textura argilosa (A) e de textura arenosa (B), submetidos a 0 e $40 \mathrm{~mm}$ de precipitação, aos 21 dias após semeadura de Ipomoea triloba. 
Garcia et al.

Nesta avaliação observa-se que os herbicidas lixiviaram de maneiras distintas nas colunas de solo, com maior lixiviação para os herbicidas diuron + hexazinone + sulfometuron-methyl (D+H+SMM) e hexazinone $(\mathrm{H})$. Esses herbicidas proporcionaram $80 \%$ de controle para a profundidade de $10 \mathrm{~cm}$ no solo de textura argilosa, independente da precipitação e no solo de textura arenosa sem precipitação (0 $\mathrm{mm})$.

Isso indica que mesmo sem chuva, em solos na capacidade de campo, esses herbicidas podem lixiviar, resultando em alto controle na camada superficial do solo. Para esses dois herbicidas, no solo de textura argilosa, a simulação de $40 \mathrm{~mm}$ de precipitação não foi suficiente para promover diferenças na lixiviação, já que chegaram até aproximadamente $10 \mathrm{~cm}$ com ou sem precipitação, causando $80 \%$ de controle. O mesmo não aconteceu no solo de textura arenosa, em que $\mathrm{D}+\mathrm{H}+\mathrm{SMM}$ e hexazinone, com $0 \mathrm{~mm}$, ficaram próximos a $10 \mathrm{~cm}$ de profundidade, enquanto que, com $40 \mathrm{~mm}$ de precipitação, chegaram à 13 e $17 \mathrm{~cm}$ de profundidade, respectivamente, causando $80 \%$ de controle (Figura 1).

Oliveira Jr. et al. (2001) caracterizaram a sorção de diferentes herbicidas em seis solos brasileiros, sendo que a sorção de bases fracas como o hexazinone, embora baixa, foi primariamente influenciada pela variação na quantidade de carbono orgânico do solo. Neste experimento, ocorreu menor lixiviação do hexazinone no solo de textura argilosa, com teor de matéria orgânica $\left(24 \mathrm{~g} \mathrm{dm}^{-3}\right) 2,4$ vezes maior do que no solo de textura arenosa (10 g $\mathrm{dm}^{-3}$ ) (Tabela 1).

De acordo com Cason et al. (2010), em solo de textura argilosa, foi observado que com a simulação de $20 \mathrm{~mm}$ de precipitação os herbicidas $\mathrm{D}+\mathrm{H}+\mathrm{SMM}$ e hexazinone provocaram fitotoxicidade nas plantas bioindicadoras (Cucumis sativus) de aproximadamente $80 \%$ até os $20 \mathrm{~cm}$ de profundidade. Quando a simulação foi de 40 $\mathrm{mm}$, os autores observaram maior lixiviação desses herbicidas, que provocaram essa mesma porcentagem de controle, até 30 e $25 \mathrm{~cm}$ de profundidade, respectivamente.

Pela Figura 1 nota-se que a porcentagem controle dos herbicidas diuron (D) e sulfometuron-methyl (SMM) ficou próxima, no máximo, aos $60 \%$ em profundidades menores que $10 \mathrm{~cm}$, indicando que os mesmos não lixiviaram em quantidades suficientes para causar a morte de todas as plantas daninhas, nem mesmo nos primeiros centímetros de profundidade do solo. No solo de textura argilosa, o herbicida diuron chegou até aproximadamente $10 \mathrm{~cm} \quad(<20 \%$ de controle) com $0 \mathrm{~mm}$ de chuva e a precipitação de $40 \mathrm{~mm}$ somente aumentou seu controle na camada inicial, evidenciada pela maior porcentagem de controle (30 a $55 \%$ ). No solo de textura arenosa ocorreu menos de $20 \%$ de controle, independentemente da presença da simulação de chuva, até aproximadamente 10 $\mathrm{cm}$ de profundidade. Inoue et al. (2008), em solo de textura argilosa, constataram que o diuron $\left(3,2 \mathrm{~kg} \mathrm{ha}^{-1}\right)$ não passou da camada de 0 a $5 \mathrm{~cm}$ mesmo com $100 \mathrm{~mm}$ de precipitação. Além disso, em solo de textura franco arenosa, na dose de $1,6 \mathrm{~kg} \mathrm{ha}{ }^{-1}$ com $80 \mathrm{~mm}$ de precipitação, somente encontraram efeito do herbicida na camada de 0 a $5 \mathrm{~cm}$ de profundidade para os bioindicadores capimbraquiária e pepino. Entretanto, na dose de 3,2 $\mathrm{kg} \mathrm{ha}^{-1}$, encontraram atividade do herbicida até as camadas de 5 a10 cm e 10 a $15 \mathrm{~cm}$, para os respectivos bioindicadores.

Cason et al. (2010) também verificaram que o herbicida diuron apresentou menor potencial de lixiviação quando comparado ao $\mathrm{D}+\mathrm{H}+\mathrm{SMM}$ e hexazinone, provocando $80 \%$ de fitointoxicação em plantas de pepino até $10 \mathrm{~cm}$ de profundidade, em solo de textura argilosa com 40 mm de precipitação. 
Garcia et al.

O SMM apresentou menos de $20 \%$ de controle até os $15 \mathrm{~cm}$. Quando houve precipitação, chegou aos $3 \mathrm{~cm}$ causando aproximadamente $60 \%$ de controle, com queda exponencial até $20 \mathrm{~cm}$. No solo de textura arenosa, este herbicida chegou até $3 \mathrm{~cm}$ causando aproximadamente $50 \%$ de controle, e apresentando queda exponencial de controle até $20 \mathrm{~cm}$, para 0 e $40 \mathrm{~mm}$ (Figura 1). Cason et al. (2010) constataram que o SMM lixiviou até aproximadamente $15 \mathrm{~cm}$ de profundidade em solo de textura argilosa, causando $20 \%$ de controle com $40 \mathrm{~mm}$ de simulação de precipitação. Em solo de textura arenosa, com essa mesma precipitação, o herbicida chegou a $20 \mathrm{~cm}$ de profundidade causando $80 \%$ de controle.

$\mathrm{Na}$ avaliação dos 30 DAS (Figura 2), observam-se as mesmas tendências de resultados dos 21 DAS, com maior lixiviação de $\mathrm{D}+\mathrm{H}+\mathrm{SMM}$ e hexazinone e menor lixiviação de diuron e SMM. Nesse tipo de experimento, quanto maior o tempo após a semeadura do bioindicador, espera-se ou a recuperação das plantas quando em contato com baixas quantidades de herbicida, ou aumento dos níveis de controle quando em contato com maiores concentrações de herbicida. De forma geral, aos 30 DAS, observou-se que os herbicidas demonstraram maior efeito em profundidades maiores, porém, ainda com baixo nível de controle. Para o solo de textura argilosa, os herbicidas $\mathrm{D}+\mathrm{H}+\mathrm{SMM}$ e hexazinone chegaram em quantidade suficiente para provocar $80 \%$ de controle até 10 e $13 \mathrm{~cm}$, respectivamente, para 0 e $40 \mathrm{~mm}$ de precipitação. Já no solo de textura arenosa, a lixiviação desses herbicidas foi mais evidente, chegando aos $20 \mathrm{~cm}$ em quantidade suficiente para causar $80 \%$ de controle.

Para os herbicidas diuron e SMM, as curvas tenderam a se aproximar para o solo de textura argilosa com $40 \mathrm{~mm}$ de chuva e para o solo de textura arenosa nas duas precipitações, o que indica menor influência das diferentes texturas sobre esses herbicidas (Figura 2), tendo a corda-de-viola como bioindicador, para as doses de 1386,9 e 33,35 g ha $\mathrm{g}^{-1}$, respectivamente.

De forma geral, a lixiviação dos herbicidas $\mathrm{D}+\mathrm{H}+\mathrm{SMM}$ e hexazinone foram semelhantes e maiores do que a lixiviação dos herbicidas diuron e SMM, para as duas precipitações e solos utilizados nesse experimento.

Monquero et al. (2008a), em experimento de lixiviação do herbicida diuron + hexazinone $\left(1170+330 \mathrm{~g} \mathrm{ha}^{-1}\right)$ em solo de textura argilosa, com $40 \mathrm{~mm}$ de precipitação, observaram que esses herbicidas chegaram até aproximadamente $17 \mathrm{~cm}$, promovendo $80 \%$ de controle de pepino. Segundo Monquero et al. (2008b), formulações de diuron + hexazinone que apresentam maior concentração de hexazinone possuem maior potencial de lixiviação.

A lixiviação do hexazinone é explicada em grande parte pela sua alta solubilidade em água aliada ao fato de estar mais presente na forma molecular (não dissociada), o que é comum na amplitude de $\mathrm{pH}$ de 4,0 a 6,5, bastante encontrados em solos brasileiros, sendo considerado um herbicida com elevado potencial de lixiviação por vários autores (Inoue et al., 2003; Cerdeira et al., 2005; Pessoa et al., 2007; Queiroz et al., 2009; Arsego, 2009).

Nesse experimento, a lixiviação de diuron não teve clara relação com as diferenças texturais dos solos. Entretanto, a baixa lixiviação do diuron, comparada com os outros herbicidas estudados, é explicada pela sua baixa solubilidade e pela sua hidrofobicidade (Prata et al., 2000; Inoue et al., 2008).

Segundo Inoue et al. (2006), a sorção de diuron foi considerada alta em todas as amostras de solos estudados em uma litosequência, não importando as características químicas das amostras, sendo o carbono orgânico do solo e as quantidades de argila as 
Garcia et al.

propriedades mais importantes que lisímetro, obtiveram que a concentração influenciaram a sorção do herbicida. Matallo et residual no solo e nas amostras de água al. (2003) constataram que a lixiviação do detectadas mostraram que a lixiviação do diuron + hexazinone está relacionada mais com diuron foi baixa em todos os casos e a sua o teor de matéria orgânica dos solos que mobilização para horizontes mais profundos qualquer outra propriedade. Já Guzzella et al. não foi considerada. (2006), em experimento com lixiviação em

A
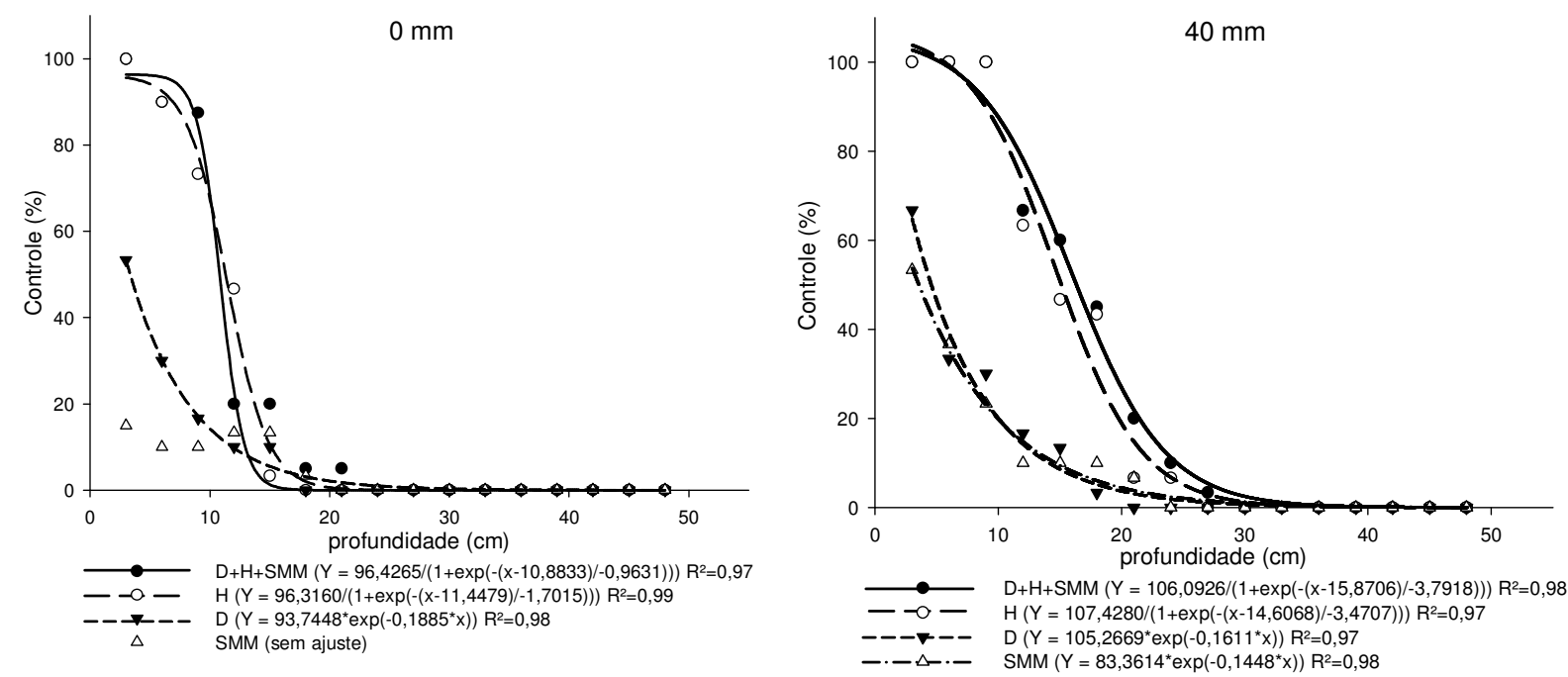

B
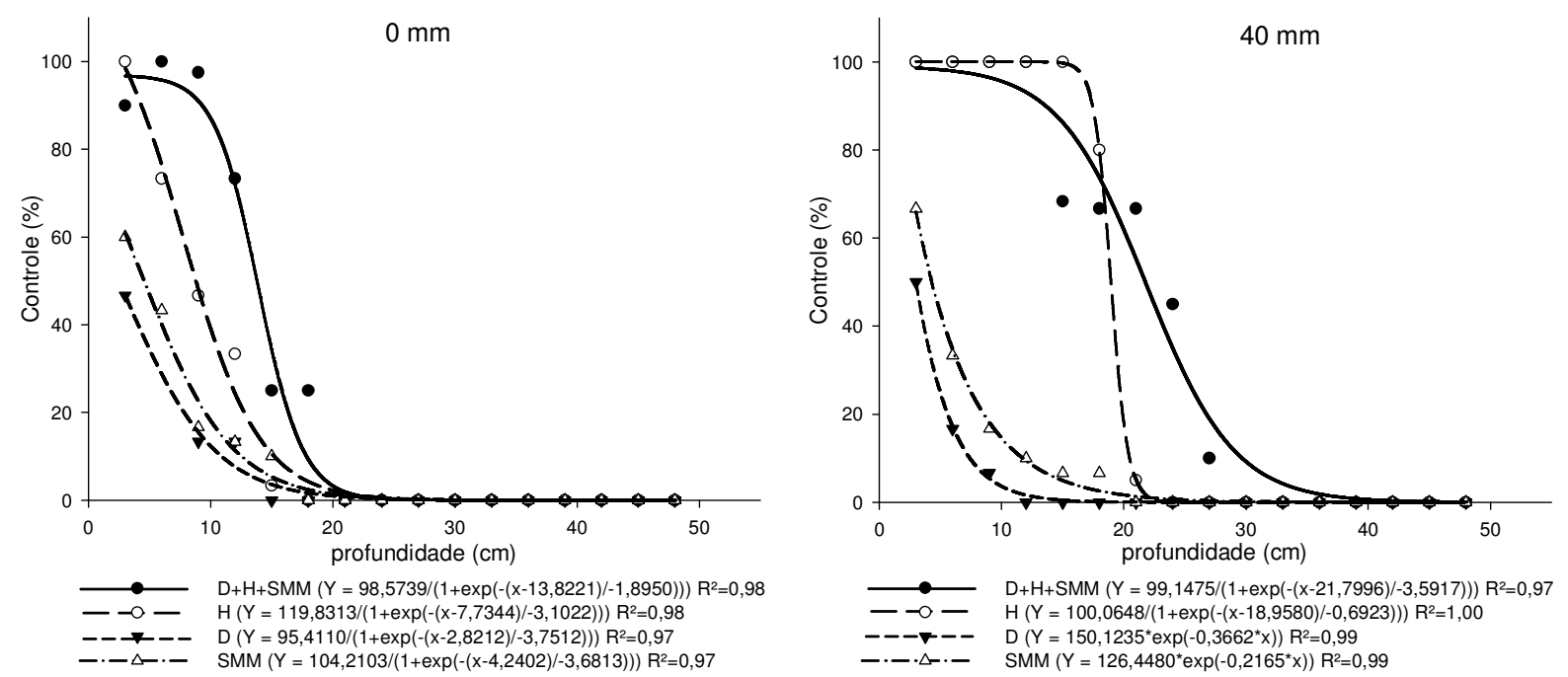

Figura 2. Lixiviação dos herbicidas diuron + hexazinone + sulfometuron-methyl (D+H+SMM), hexazinone (H), diuron (D) e sulfometuron-methyl (SMM) no solo de textura argilosa (A) e de textura arenosa (B), submetidos a 0 e $40 \mathrm{~mm}$ de precipitação, aos 30 dias após semeadura de Ipomoea triloba. 
Garcia et al.

Entretanto, apesar da matéria orgânica geralmente fornecer a maioria dos sítios de adsorção nos solos, a correlação entre adsorção e matéria orgânica depende mais ou menos da natureza do herbicida e do solo, e a influência positiva da matéria orgânica não é sempre óbvia (Kah \& Brown, 2006).

Para solos com o pH menor do que o pKa do sulfometuron-methyl, ele estará em sua forma não iônica e estará sujeito às mesmas forças de sorção que atuam em um herbicida não dissociável (Koskinen et al., 1996). Desta forma, neste experimento os solos utilizados apresentaram pHs de 4,8 e 4,5 (Tabela 1), logo o sulfometuron-methyl (pKa 5,2) está em sua forma não iônica e por isso tende a lixiviar menos, pois a forma aniônica é transportada mais livremente através da solução do solo. $\mathrm{Ou}$ seja, para o sulfometuron-methyl, a sorção no solo é baixa e o potencial de lixiviação é maior em solos alcalinos do que em solos ácidos (Oliveira Jr. et al., 2001).

A tendência da lixiviação dos herbicidas $\mathrm{D}+\mathrm{H}+\mathrm{SMM}$ e hexazinone serem iguais (Figuras 1 e 2), aliada ao fato de que diuron e SMM tiveram baixas tendências de lixiviação nesse experimento, indica que a maior parte da lixiviação encontrada para o herbicida D+H+SMM é explicada pelo hexazinone presente nessa formulação.

\section{Conclusões}

A formulação comercial dos herbicidas [diuron+hexazinone+sulfometuron-methyl] e o hexazinone apresentaram maior tendência de lixiviação, sendo esta facilitada no solo de textura arenosa. A lixiviação dos herbicidas diuron e sulfometuron-methyl foi baixa, não tendo relação clara com as diferentes texturas e simulações de precipitação utilizadas.

\section{Referências}

ARSEGO, I.B. Sorção dos herbicidas diuron e hexazinone em solos de texturas contrastantes. 2009. 66p. Dissertação (Mestrado em Fitotecnia) - Escola Superior de Agricultura "Luiz de Queiroz". Universidade de São Paulo, Piracicaba, 2009.

CASON, J.B. et al. Lixiviação e persistência de diuron+hexazinone+sulfometuron, hexazinone, sulfometuron e diuron. In: CONGRESSO BRASILEIRO DA CIÊNCIA DAS PLANTAS DANINHAS, 27., Ribeirão Preto, 2010. Resumos... Ribeirão Preto: SBCPD, 2010. p.3396-3400.

CERDEIRA A.L. et al. Herbicide leaching on a recharge area of the Guarany Aquifer in Brazil. Journal of Environmental Science and Health, v.40, n.1, p.159-165, 2005.

GEBLER, L.; SPADOTTO, C.A. Comportamento ambiental dos herbicidas. VARGAS, L.; ROMAN, E.S. (Ed.). Manual de manejo e controle de plantas daninhas. Passo Fundo: Embrapa Trigo, p.39-69, 2008.

GUZZELLA, L. et al. Fate of diuron and linuron in a field lysimeter experiment. Journal of Environmental Quality, v.35, n.1, p.312-323, 2006.

INOUE, M.H. et al. Critérios para avaliação do potencial de lixiviação dos herbicidas comercializados no estado do Paraná. Planta Daninha, v.21, n.2, p.313-323, 2003.

INOUE, M.H. et al. Sorption-desorption of atrazine and diuron in soils from southern Brazil. Journal of Environmental Science and Health, v.41, n.5, p.605-621, 2006.

INOUE, M.H. et al. Lixiviação e degradação de diuron em dois solos de textura contrastante. Acta Scientiarum. Agronomy, v.30, n.5, p.631-638, 2008.

KAH, M.; BROWN, C.D. Adsorption of ionisable pesticides in soils. Reviews of Environmental Contamination \& Toxicology, v.188, n.1, p.149-217, 2006.

KOSKINEN, W.C.; STONE, D.M.; HARRIS, A.R. Sorption of hexazinone, sulfometuron- 
Garcia et al.

methyl, and tebuthiuron on acid, low base saturated sands. Chemosphere, v.32, n.9, p.1681-1689, 1996.

MATALLO, M.B. et al. Lixiviação dos herbicidas Tebutiuron e Diuron em colunas de solo. Pesticidas: Revista de Ecotoxicologia e Meio Ambiente, v.13, n.1, p.83-90, 2003.

MONQUERO, P.A. et al. Lixiviação de clomazone + ametryn, diuron + hexazinone e isoxaflutole em dois tipos de solo. Planta Daninha, v.26, n.3, p.685-691, 2008a.

MONQUERO, P.A. et al. Potencial de lixiviação de herbicidas no solo submetidos a diferentes simulações de precipitação. Planta Daninha, v.26, n.2, p.403-409, 2008 b.

OLIVEIRA JR., R.S.; KOSKINEN, W.C.; FERREIRA, F.A. Sorption and leaching potential of herbicides on brazilian soils. Weed Research, v.41, n.2, p.97-110, 2001.

PESSOA, M.C.P.Y. et al. Avaliação do potencial de transporte de agrotóxicos usados no Brasil por modelos screening e planilha eletrônica. Boletim de Pesquisa e Desenvolvimento, 44. Embrapa Meio Ambiente, Jaguariúna. 24p, 2007.

PRATA, F. et al. Degradação e adsorção de diuron em solos tratados com vinhaça. Revista Brasileira de Ciência do Solo, v.24, n.1, p.217-223, 2000.

QUEIROZ, S.C.N. et al. Comportamento do herbicida hexazinone em área de recarga do aquífero guarani cultivada com cana-de-açúcar. Química Nova, v.32, n.2, p.378-381, 2009.

REGITANO, J.B. et al. Imazaquin mobility in tropical soils in relation to soil moisture and rainfall timing. Weed Research, v.42, n.4, p.271-279, 2002.

UNIVERSITY OF HERDFORTSHIRE. Pesticide Properties Database. Disponível em:

$<$ http://sitem.herts.ac.uk/aeru/footprint/index2. htm>. Acesso em: 4 nov. 2011. 